\title{
Calanus hyperboreus and the lipid pump
}

\section{Visser, Andre; Grønning, Josephine Bøgeskov; Jonasdottir, Sigrun}

\section{Published in:}

Limnology and Oceanography

Link to article, DOI:

10.1002/Ino.10492

Publication date:

2017

\section{Document Version}

Publisher's PDF, also known as Version of record

Link back to DTU Orbit

\section{Citation (APA):}

Visser, A., Grønning, J. B., \& Jonasdottir, S. (2017). Calanus hyperboreus and the lipid pump. Limnology and Oceanography, 62(3), 1155-1165. https://doi.org/10.1002/Ino.10492

\section{General rights}

Copyright and moral rights for the publications made accessible in the public portal are retained by the authors and/or other copyright owners and it is a condition of accessing publications that users recognise and abide by the legal requirements associated with these rights.

- Users may download and print one copy of any publication from the public portal for the purpose of private study or research.

- You may not further distribute the material or use it for any profit-making activity or commercial gain

- You may freely distribute the URL identifying the publication in the public portal

If you believe that this document breaches copyright please contact us providing details, and we will remove access to the work immediately and investigate your claim. 


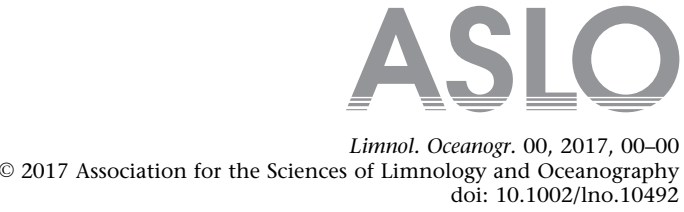

\title{
Calanus hyperboreus and the lipid pump
}

\author{
Andre W. Visser, ${ }^{*}$ Josephine Grønning, Sigrún Huld Jónasdóttir
}

VKR Centre for Ocean Life, National institute of Aquatic Resources, Technical University of Denmark, Kgs. Lyngby, Denmark

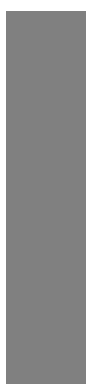

\begin{abstract}
Lipid-fuelled overwintering by copepods can be a regionally important contribution to carbon sequestration in the deep oceans. Here, we estimate the contribution for Calanus hyperboreus, found in abundance in the northern reaches of the North Atlantic and Arctic Ocean. Estimates for regions with high overwintering populations, Fram Strait, Greenland Sea and Iceland Sea lie between $3.5 \mathrm{gC} \mathrm{m}^{-2} \mathrm{yr}^{-1}$ and $^{6.0} \mathrm{gC} \mathrm{m}^{-2} \mathrm{yr}^{-1} \mathrm{at}$ depths of 1000-3000 m, comparable to the flux of detrital organic carbon at commensurate depths. Apart from the variation in the abundance of overwintering populations, these estimates are most sensitive to mortality rates. We present a general model based on metabolic theory and isomorphism that can be used to constrain estimates for data poor species in other parts of the global ocean.
\end{abstract}

In various parts of the world's oceans, large populations of zooplankton undertake seasonal migrations to depths of a $1000 \mathrm{~m}$ or more where they overwinter for several months of the year. These seasonal migrations have been identified as a potentially significant element of the biological pump, promoting the sequestration of carbon in the deep ocean (Bradford-Grieve et al. 2001; Kobari et al. 2008; Jónasdóttir et al. 2015). An important aspect of this is the active transport of stored lipids by individual zooplankters as they migrate from the surface ocean to their overwintering depths below the permanent thermocline. These stored lipids subsequently fuel respiration during winter. Even with markedly lower metabolic rates, the extended periods spent at depth, means that a significant fraction of the transported lipids are converted to $\mathrm{CO}_{2}$, and remain at depth after the individual returns to the surface the following spring. For Calanus finmarchicus, a copepod species found in abundance across the North Atlantic, this process-the so called lipid pump (Jónasdóttir et al. 2015)—can constitute a substantial contribution to the local carbon flux. An important feature of lipid-fuelled overwintering is that unlike the flux of detrital material, it transports carbon directly to the deep ocean with very little loss on the way. In addition, it decouples the vertical flux of carbon from that of the main limiting nutrients for primary production (e.g., nitrogen, phosphorus, iron). This makes the lipid pump not only particularly efficient in carbon sequestration, it also make it difficult to document

*Correspondence: awv@aqua.dtu.dk

Additional Supporting Information may be found in the online version of this article.
(Jónasdóttir et al. 2015) as it leaves little trace in the nutrient budgets of the surface ocean.

A full global accounting of the lipid pump thus remains elusive as it depends on the abundance of a wide variety of resident zooplankton species often with quite varied life history strategies. Ecologically similar species such as Calanus hyperboreus in the Nordic Seas (Conover 1992; Hirche 1997), Neocalanus tonus, Calanoides acutus, Rhincalanus gigas, and Calanus propinquus in the Southern Ocean (Bathmann et al. 1993; Atkinson 1998; Bradford-Grieve et al. 2001), Neocalanus plumchrus, Neocalanus cristatus, and Eucalanus bungii in the North Pacific (Miller et al. 1984; Kobari et al. 2008), and Calanoides carinatus and Eucalanus monachus in the Indian Ocean (Smith 1995) are all candidate species in that they engage in lipid-fuelled diapause in deep ocean basins. While this list is by no means exhaustive, it does illustrate the challenge of compiling a global inventory.

Our primary motive here is to document the contribution from one of these, C. hyperboreus in the North Atlantic and adjacent Seas. The method we use is cast in a general manner that can serve template for other species in other regions of the global ocean. In particular, we appeal to the metabolic theory of ecology (Brown et al. 2004) which can provide estimates of important vital rates and processes that may be poorly constrained by observations. Specifically, respiration rates for overwintering individuals can be estimated from a few observations and extended across different temperatures, different sized species and life stages. Respiration rates can also constrain the length of diapause given observations of lipid reserves (Saumweber and Durbin 2006; Maps et al. 2010; Pierson et al. 2013).

In general, estimates of the sequestered carbon by seasonal migration are based on the difference between how much 
is transported down in the late summer, and how much comes back to the surface in spring. This depends on the stage specific abundances of the of overwintering individuals, their respiration integrated over their respective overwintering durations, corrected for the mortality of individuals at depth, especially spent females, and discounted for the eggs spawned at depth that return to the surface in spring. Different aspects of this carbon budget become important for different species in different regions. For instance, N. tonus in the Southern Ocean has a 1 yr life cycle where the copepodite stage $\mathrm{CV}$ overwinters, molts into an adult, spawns and then expires at depth (Ohman et al. 1989). In this case, while details of respiration and mortality may be sketchy, the net carbon flux can be relatively easily closed as being essentially the difference between the active downward transport by migrating CV's and the upward drift of eggs the following spring (Bradford-Grieve et al. 2001). In other instances such as for C. finmarchicus in the North Atlantic, females return to the surface to spawn, so that overwintering duration and respiration rate become important governing factors. The life history strategy of C. hyperboreus, includes elements of both these cases, and requires estimates of deep water egg production, mortality and respiration for a full evaluation of its overwintering carbon budget. The C. hyperboreus case thus presents an ideal opportunity to outline general principles for estimating carbon sequestration by seasonally migrating zooplankton.

\section{Methods}

\section{Compilation of $C$. hyperboreus observations}

Along with its cousin species C. finmarchicus, Calanus glacialis and Calanus helgolandicus, C. hyperboreus plays a key role in the ecology of the North Atlantic. C. hyperboreus is the largest of these species. Through its life history strategy combining both capital breeding and overwintering diapause, it is well adapted to the strong seasonal pulsing of food availability in the boreal reaches of the North Atlantic and adjacent seas. It is particularly abundant-in terms of biomass-in the deep basins of the Nordic Seas, Greenland Basin and Iceland Sea, while its smaller cousin, C. glacialis occupies the shallower shelf sea zones of these regions.

C. hyperboreus has a multi-year (2-6 yr) life cycle. Females spawn lipid rich eggs at depth that are positively buoyant and drift toward the surface (Hirche and Niehoff 1996; Swalethorp et al. 2011) where they develop into nauplii. Its maturation through naupliar stages to an early copepodite stage is completed within one season after which it overwinters as a CIII or CIV (Falk-Petersen et al. 2009). The development rate and subsequent ontogeny of overwintering varies from place to place likely in response to the intensity and duration of the vernal bloom, as well as individual plasticity in the allocation of resources to somatic growth or lipid reserves. A typical sequence would have an individual overwinter 3-4 times, as a CIII, CIV, CV, and adult. There are no clear reports of what happens to the females after spawning. It is generally understood that spent adults expire at depth, however observations of spent $C$. hyperboreus females in surface waters in spring suggests that at least some fraction may ascend, feed and build up lipid stores again and go through a second overwintering and reproduction cycle (Swalethorp et al. 2011; Hirche 2013).

The overwintering stages (CIII, CIV, CV, and adult) all store the lipids in the form of wax esters in an internal oil sac. The oil sac can occupy a considerable fraction of the internal volume, and can constitute up to $60 \%$ of the total dry weight of individuals across all stages. C. hyperboreus overwinters typically at depths between $600 \mathrm{~m}$ and $3000 \mathrm{~m}$ (Hirche 1997; Falk-Petersen et al. 2009), although, overwintering depths vary depending on location, ontogeny, and season. In some instances, overwintering populations appear to reside in a relatively thin layer a few tens of meters thick just above the seabed at some 1000s m depth (Auel et al. 2003; Hirche et al. 2006).

Distribution, abundance and stage composition of C. hyperboreus was attained through data mining of most of the available literature. Data from over 50 papers were compiled standardizing abundances to numbers per $\mathrm{m}^{2}$. If numerical data were not presented we used the image processing programme Image-J (Abràmoff et al. 2004) for reading abundances and station locations from graphs and maps. We refer to the Supporting Information material for a complete list of publications from which data has been extracted for this analysis, as well as a compilation of these observations. For the calculation of carbon sequestration we restricted the use of data from locations over $600 \mathrm{~m}$ in depth as sequestration will not take place on shallow overwintering areas.

\section{Model}

The sequestering of carbon by $C$. hyperboreus, and indeed for many of the other species that can potentially contribute to the lipid pump, depends on several parameters that are only poorly constrained. For instance, respiration rate during diapause has been measured only for a few species (Hirche 1997; Ingvarsdóttir et al. 1999; Auel et al. 2003) and then only in specific locations and after the animals have been brought to surface. Likewise, the regular winter surveys required to map out the depth and duration of diapause have only been conducted in a few cases, e.g., C. finmarchicus (Heath et al. 2000). In this, we can appeal to metabolic theory to help fill in the knowledge gaps. In particular, the thermal and allometric aspects of metabolic rates appear to follow a near universal functional form. Keiber's law (Kleiber 1947) for instance suggests that the metabolic rate of an organism scales as a $3 / 4$ power of its mass. In addition, metabolic rates tend to increase with temperature (Arrhenius 1889) providing a thermo-allometric relationship 


$$
r(M, T)=b \cdot M^{3 / 4} \exp \left(E \cdot\left(T-T_{0}\right) /\left(k \cdot T \cdot T_{0}\right)\right)
$$

where $M[\mu \mathrm{gC}]$ is mass, $r\left[\mu \mathrm{gC} \mathrm{s}^{-1}\right]$ is respiration rate, $T[\mathrm{~K}]$ is temperature, $b\left[\mu \mathrm{gC}^{1 / 4} \mathrm{~s}^{-1}\right]$ is a universal scaling constant, $E$ $[\mathrm{eV}]$ is the activation energy and $k\left[\mathrm{eV} \mathrm{K}^{-1}\right]$ the Boltzmann constant. $T_{0}$ is a base temperature, usually taken as $T_{0}=273 \mathrm{~K}$. The metabolic theory of ecology (Brown et al. 2004) provides a theoretical foundation for this relationship and it is fairly well supported by observations for life forms in their natural thermal range, from unicellular organisms, to vascular plants to bird, fish and mammals (Gillooly et al. 2001). When applied within taxa (e.g., Calanoid copepods), the fit is even more robust (Kiørboe and Hirst 2014).

In applying this scaling to an overwintering copepod, we should distinguish between two different types of mass; its vital (or structural) mass $m$ and its mass of stored lipid reserves $w$. Notably, while Eq. 1 relates metabolic rate to total mass $(M=m+w)$, one could reasonably assume that base metabolism is largely dependent only on vital mass, while the fuel to cover this metabolism comes largely from lipid reserves mass. This suggests a linear decrease in lipid mass over time that follows

$$
w(t)=w(0)-b \cdot f(T) \cdot m^{3 / 4} \cdot t
$$

where $f$ is a dimensionless function depending only on temperature. Note that this is a departure from other model frameworks (Saumweber and Durbin 2006; Maps et al. 2014) who do not make the distinction between vital and storage mass and thus arrive at an exponential decay of total mass with time. While this does not invalidate these analysesthe exponential decay can be extremely flat approximating a linear decrease over the range of interest-it does make the subsequent interpretation overly cumbersome and difficult to extrapolate across species and stages.

Given their shared evolutionary history, one might expect that metabolic rate for various copepod species in diapause to be governed by a similar thermo-allometric scaling law. A review (Maps et al. 2014) of measured metabolic rates for dormant copepods across the global ocean provides estimates of $b=(2.3 \pm 0.4) \times 10^{-7} \mu \mathrm{gC}^{1 / 4} \mathrm{~s}^{-1}$ and activation energy $E=0.6 \pm 0.1 \mathrm{eV}$.

The physical characteristics of $C$. hyperboreus (i.e., prosome length, dry weight, carbon content, lipid content) all vary considerably from place to place and over time of year as well as across life stages. In order to uncover some relatively general principles, we appeal to isomorphism: that is, across different overwintering stages and even between different pelagic copepod species, individuals may vary in size but their basic physical design remains remarkably constant (Kiørboe 2008). In C. hyperboreus for instance, apart from size, the only significant taxonomic difference across stages CIII-CV is the number of segments on the tail. An outcome of isomorphism is that any physical characteristic such as structural mass would scale with the cube of any linear dimension. For instance, all things being equal, dry weight $(d[\mathrm{mg}])$ and prosome length $(p[\mathrm{~mm}])$ should be related as $d=c p^{3}$.

Such a relationship is at first glance not supported by empirical evidence. Observations from the Arctic (Hirche and Mumm 1992) show a power law relationship between prosome length and dry weight with a coefficient between 3.3 and 3.5 for C. hyperboreus from stage CIII to females (Fig. 2). While establishing the exact form of a power law is in itself notoriously difficult, we contend that there is a systematic bias in observations that will tend to steepen the power law fit. In Fig. 2, we also plot the wax ester content (based on oil sac area) drawn from observations in the Labrador, Irminger, Iceland and Greenland Seas. In all observed individuals, wax ester content can constitute a significant fraction of the dry weight-from $60 \%$ to $20 \%$, and a scaling law regression fit shows a similar power law relationship with prosome length as dry weight. The sampling bias comes about because smaller stages deplete their reserves to relatively lower levels (e.g., from $60 \%$ to $20 \%$ over a winter season) than larger animals (e.g., $60 \%$ to only $40 \%$ over the same period). Sampling at any given time would tend turn up more depleted small organisms than large animals. The only way to circumvent this bias is to measure the weight and lipid content of individuals at precise milestones in their life cycle-immediately after they emerge from diapause before they start to feed, or immediately before they descend to depth at the end of the growing season. Indeed, one study that seeks to describe seasonal variations in allometric carbon content (Forest et al. 2011) suggests a relationship more in line with a cubic power law (i.e., consistent with isomorphic scaling), although this is by no means conclusive.

We propose the following model, founded on the principle of isomorphism, as a parsimonious alternative that conforms to observations and that can find a broader application for other data poor species. First, there is a basic body plan by which structural (vital) mass $(m[\mu \mathrm{gC}])$ scales with prosome length:

$$
m=\alpha p^{3}
$$

Second, there is a potential maximum and minimum reserve (wax ester) mass $[\mu \mathrm{gC}]$ respectively given by

$$
\begin{gathered}
w_{\max }=\beta p^{3} \\
w_{\min }=\delta \beta p^{3}
\end{gathered}
$$

Thus the observed wax ester content $(\omega[\mu \mathrm{g}])$ would lie between $\beta p^{3} / \varepsilon$ and $\delta \beta p^{3} / \varepsilon$ where $\varepsilon$ is the carbon fraction of wax ester mass. Using $\varepsilon=0.8$ (calculated from Kattner and Hagen 2009), a reasonable fit for observations (Fig. 2) is given by $\beta=7.2\left[\mu \mathrm{gC} \mathrm{mm}^{-3}\right]$ and $\delta=0.2$. Similarly, total dry 
mass $(d[\mu \mathrm{g}])$ would lie between $\left(\alpha / \varepsilon^{\prime}+\beta / \varepsilon\right) p^{3}$ and $\left(\alpha / \varepsilon^{\prime}+\delta \beta /\right.$ $\varepsilon) p^{3}$ where $\varepsilon^{\prime}=0.7$ is the carbon fraction of structural mass. Again a reasonable fit is given by $\alpha=4.2\left[\mu \mathrm{gC} \mathrm{mm}^{-3}\right]$.

It has been suggested that the emergence from diapause is initiated when the reserve levels reach a critical percentage of the overall body mass (Saumweber and Durbin 2006; Maps et al. 2010). Given the above scaling, this would give an estimate of diapause length as

$$
D_{i}=\min \left(\frac{(1-\delta) w_{i, \max }}{b f(T) m_{i}^{3 / 4}}, D_{\max }\right)
$$

where the subscript $i$ indicates different values for different stages. $D_{\max }$ is a maximum diapause duration, chosen to be representative of particular populations. In effect, this means that large stages do not deplete their resources to the same level as smaller stages, or, if they do, then small stages remain in diapause for a shorter period than larger stages. For $C$. hyperboreus, the diapause duration of all stages appears to be at least 8 months (Hirche 1997) in various locations across the Arctic Ocean and Nordic Seas, with some observations suggesting diapause duration of up to 10 months. For the purposes of this work, we set $D_{\max }=240 \mathrm{~d}$.

For specific respiration rate, we choose two representative values of $b ; 2.5 \times 10^{-7}$ and $5 \times 10^{-7} \mu \mathrm{gC}^{1 / 4} \mathrm{~s}^{-1}$. The latter of these $\left(b=5 \times 10^{-7} \mu \mathrm{gC}^{1 / 4} \mathrm{~s}^{-1}\right)$ correspond to the value reported by Maps et al. (2014), duly multiplied by the factor $\left(1+w_{\max } / m\right)^{3 / 4}$ to account for our use of structural mass rather than total mass in allometric scaling, and assuming the measured animals had maximum lipid reserves. This value of $b$ however allows for only relatively short diapause duration-7 months for females and only 3 months for CIII-significantly less than observed (Hirche 1997).

To contrast this, we also consider a lower metabolic rate $\left(b=2.5 \times 10^{-7} \mu \mathrm{gC}^{1 / 4} \mathrm{~s}^{-1}\right)$, a value which reproduces diapause duration close to observed, and results in a respiration rate of about $4 \mu \mathrm{gC} \mathrm{d}^{-1}$ for females consistent with the lower of the values reported by Auel et al. (2003). It is also consistent with the value reported by Maps et al. (2014) when scaled by $\left(1+w_{\min } / m\right)^{3 / 4}$, i.e., assuming the measured animals had minimum lipid reserves.

The number of eggs produced by a female at the end of diapause is not easily measured. With no better information, we assume a female allocates $C_{\text {egg }}=900 \mu \mathrm{gC}$ to egg production at depth. This is based on laboratory studies (Conover 1967; Hirche and Niehoff 1996; Plourde et al. 2003; Halvorsen 2015) which suggest an annual egg production of around 1800 (range: 400-3400) per female, and an egg carbon content of around $0.5 \mu \mathrm{gC}$ (Jung-Madsen et al. 2013).

In addition to respiration, overwintering individuals also suffer mortality, whether from starvation, predation or pathogens (Daase et al. 2014). These rates, particularly in deep overwintering populations are poorly constrained. In this, we appeal to estimates for ecologically similar species
E. bungii which during diapause in the North Pacific show a wide range from $0.01 \mathrm{~d}^{-1}$ to $0.001 \mathrm{~d}^{-1}$ (Tsuda et al. 2004).

An estimate of annual carbon flux to depth, $Q\left[\mathrm{gC} \mathrm{m}^{-2}\right.$ $\mathrm{yr}^{-1}$ ] can be calculated as the sum of respiration, mortality and egg production following

$$
\begin{gathered}
Q=\sum_{\text {stage }} A_{i} \frac{\left(1-e^{-\mu_{i} D_{i}}\right)}{\mu_{i} D_{i}} r_{i} D_{i}+\sum_{\text {stage }} A_{i}\left(1-e^{-\mu_{i} D_{i}}\right)\left(m_{i}+w_{i, \max }-r_{i} D_{i} / 2\right) \\
+\xi A_{\mathrm{F}} e^{-\mu_{\mathrm{F}} D_{\mathrm{F}}}\left(m_{\mathrm{F}}+w_{\mathrm{F}, \max }-r_{\mathrm{F}} D_{\mathrm{F}}-C_{\mathrm{egg}}\right)
\end{gathered}
$$

Here, $A_{i}$ is the abundance [ind $m^{-2}$ ] of the various stages of an overwintering population that initially descend at the start of the overwintering period, $\mu_{i}$ its mortality rate, $D_{i}$ its overwintering duration (Eq. 5), and $r_{i}$ its respiration rate during diapause (cf Supporting Information material). The second term represents the contribution from mortality and in the third term, the factor $\xi$ represents the fraction of females that expire at depth after spawning.

Finally, we note that the measured abundances are more representative of the average number of individuals $\bar{A}_{i}$ found at depth than they are of initial values $A_{i}$. Indeed, where multiple observations have been taken during diapause, we have expressly taken the average of these. Given a specific mortality rate, we can relate average and initial estimates as

$$
\bar{A}_{i}=A_{i} \frac{\left(1-e^{-\mu_{i} D_{i}}\right)}{\mu_{i} D_{i}}
$$

so that in terms of average abundances, the flux is given by

$$
\begin{aligned}
Q & =\sum_{\text {stage }} \bar{A}_{i} r_{i} D_{i}+\sum_{\text {stage }} \bar{A}_{i} \mu_{i} D_{i}\left(m_{i}+w_{i, \text { max }}-r_{i} D_{i} / 2\right) \\
& +\xi \bar{A}_{\mathrm{F}} \frac{\mu_{\mathrm{F}} D_{\mathrm{F}} e^{-\mu_{\mathrm{F}} D_{\mathrm{F}}}}{1-e^{-\mu_{\mathrm{F}} D_{\mathrm{F}}}}\left(m_{\mathrm{F}}+w_{\mathrm{F}, \text { max }}-r_{\mathrm{F}} D_{\mathrm{F}}-C_{\text {egg }}\right)
\end{aligned}
$$

\section{Results}

The meta analysis resulted in three types of distribution information on C. hyperboreus, (1) total abundance, (2) stage composition and abundance and (3) studies reporting only presence (Fig. 1). We could use eight regions where information on abundance and stage composition during overwintering were sufficient for our analysis. These include Nansen Basin, Iceland Sea, West Spitzbergen Current, Greenland Sea, Fram Strait, East Norwegian Sea, West Norwegian Sea, and the Norwegian Sea Basin (Table 1). The stage composition is the average winter composition in the areas (October-February), compiled from the sampling depths available, preferentially over $600 \mathrm{~m}$ depth. We refer to Supporting Information material for the complete compilation of yearly and seasonal abundances and stage structure over the different oceanic regions (Supporting Information Tables S1-3; Supporting Information Fig. S1). 


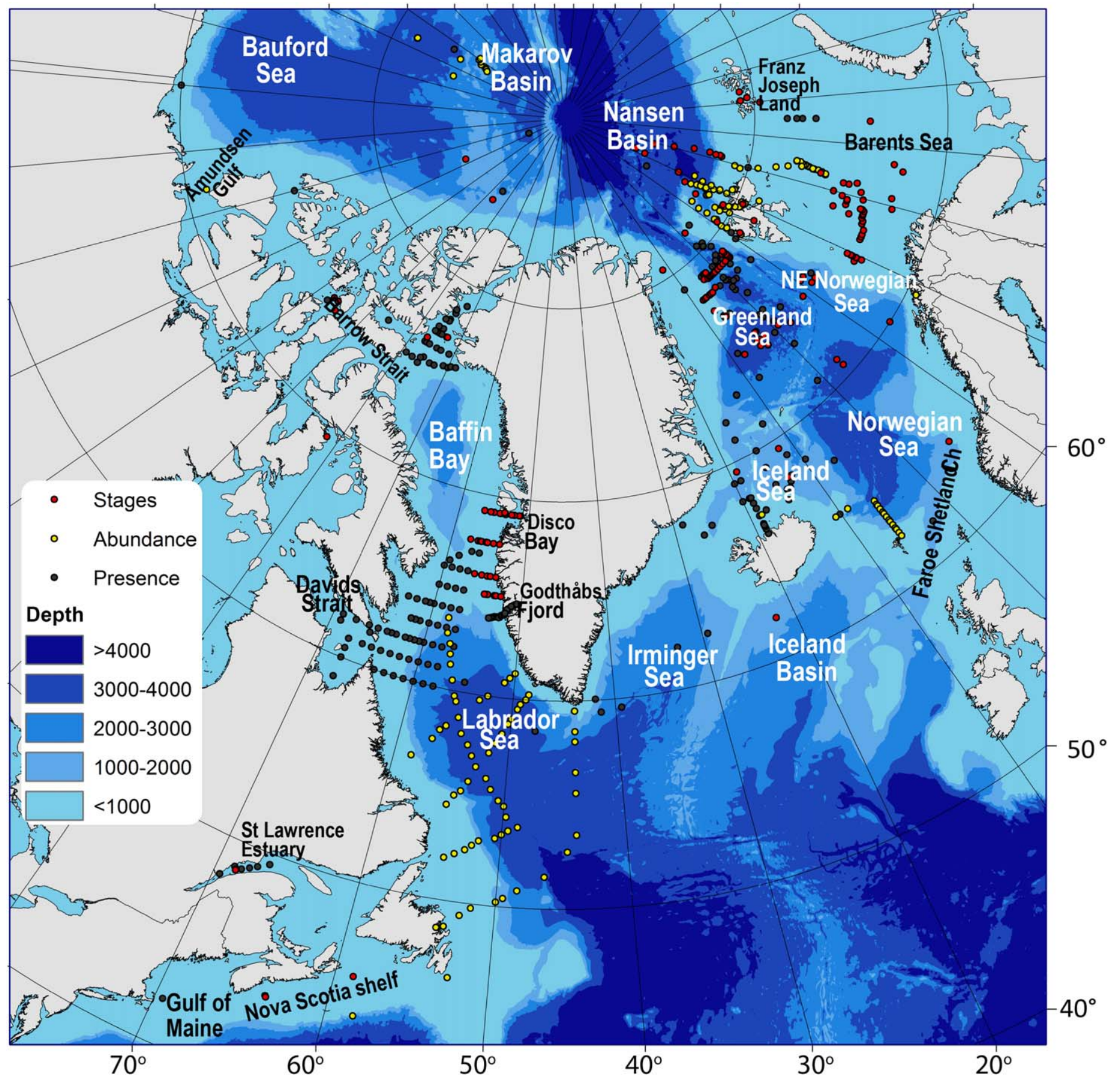

Fig. 1. C. hyperboreus distribution based on published sampling and notations of presence. Different symbols indicate stations giving stage abundances (Stages), abundance only (Abundances) and sampling without reporting on abundances (Presence). Source of the compilation is detailed in the Supporting Information Tables S1-S3. [Color figure can be viewed at wileyonlinelibrary.com]

Model results for the eight regions are summarized in Fig. 2. Estimated respiration rates for individuals range between $0.4 \mu \mathrm{gC} \mathrm{d}^{-1}$ and $4.0 \mu \mathrm{gC} \mathrm{d}^{-1}$ depending on stage and temperature. These estimates are consistent with some of the very few observations showing dormant $C$. hyperboreus $\mathrm{CV}$ and females respiring at $4-8 \mu \mathrm{gC} \mathrm{d}^{-1}$ (Auel et al. 2003). Using the conservative lower metabolic rate estimate, $\left(b=2.5 \times 10^{-7}\right.$ $\left.\mu \mathrm{gC}^{1 / 4} \mathrm{~s}^{-1}\right)$, maximum assumed overwintering duration $\left(D_{\max }\right)$ of 8 months is achieved in all locations except for CIII stage which can only remain in diapause for around 7 months assuming a minimum wax ester reserve level of $20 \%$, consistent with field observations (Hirche 1997). Integrating 


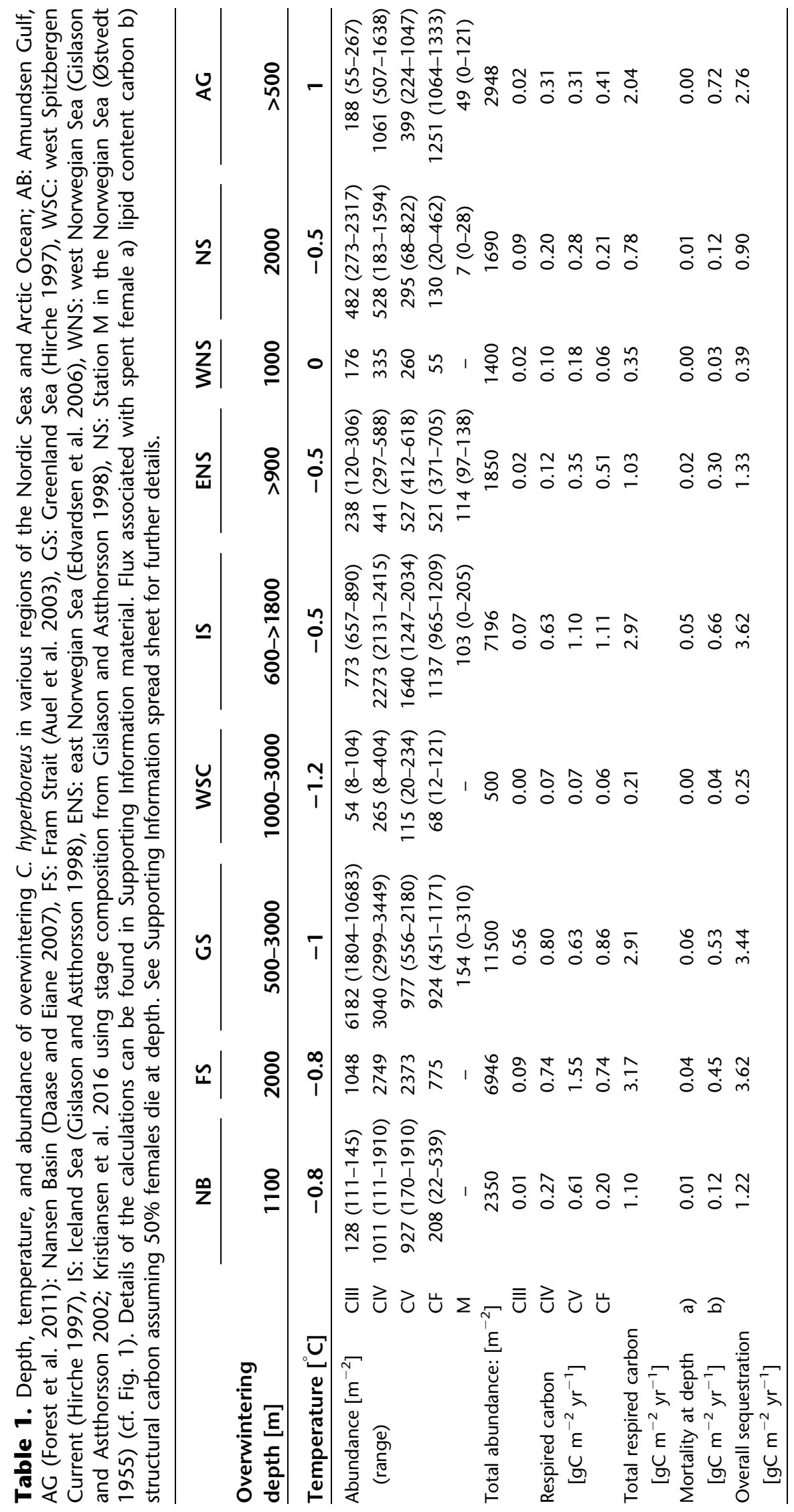




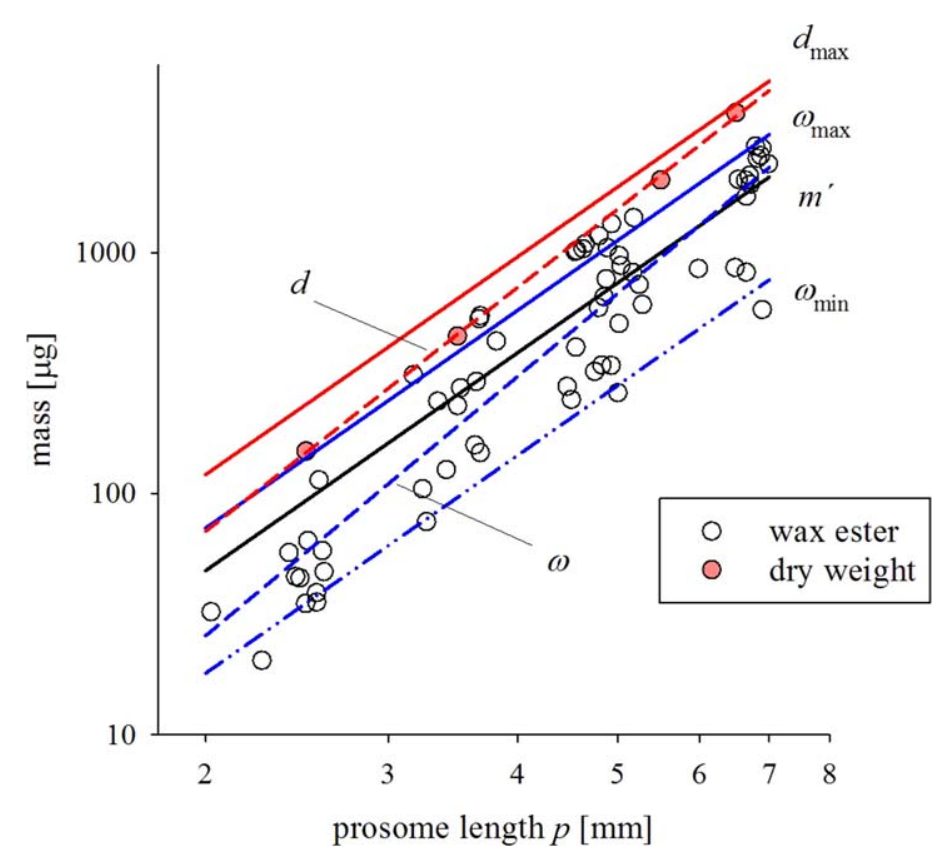

Fig. 2. Dry mass $(d[\mu \mathrm{g}])$ and wax ester content $(\omega[\mu \mathrm{g}])$ as functions of prosome length $(p[\mathrm{~mm}])$ across stages CIII-CF for $C$. hyperboreus. Dry mass are averaged literature estimates (Hirche 1997; Scott et al. 2000; Auel et al. 2003; Falk-Petersen et al. 2009) while wax ester content are our own observations. Power law regressions to observations suggest $d=6.79 p^{3.36}$ and $\omega=2.17 p^{3.57}\left(R^{2}=0.86\right)$. Superimposed are our estimates of the maximum and minimum wax ester content $\omega_{\max }=(\beta / \varepsilon) p^{3}$ and $\omega_{\min }=(\delta / \varepsilon) p^{3}$ respectively, and vital mass $m^{\prime}=\left(\alpha / \varepsilon^{\prime}\right) p^{3}$ based on isometric scaling, with parameters $\alpha=4.2 \mu \mathrm{gC} \mathrm{mm}{ }^{-3}, \beta=7.2 \mu \mathrm{gC} \mathrm{mm}$ and $\delta=0.2$, and for a lipid mass carbon content of $\varepsilon=0.8[\mu \mathrm{gC} / \mu \mathrm{g}]$ and a vital mass carbon content of $\varepsilon^{\prime}=0.7[\mu \mathrm{gC} / \mu \mathrm{g}$ ]. [Color figure can be viewed at wileyonlinelibrary.com]

respiration rate over diapause duration and average abundance of the various overwintering stages gives estimates of respired carbon ranging as high as $3.1 \mathrm{gC} \mathrm{m}^{-2} \mathrm{yr}^{-1}$, a complete breakdown of the various contributions to the carbon flux, as well as estimates for the higher metabolic rate constant can be found in the Supporting Information material.

The other component of carbon sequestration comes about by mortality, for which there are two principle sources: general mortality during the entire diapause period, and the mortality of spent females at depth after spawning. Assuming half the female population dies after spawning (i.e., $\xi=0.5$ ) increases the carbon sequestration estimate by about $30 \%$. Most of this extra sequestration comes from the structural mass of the spent females since their reserve mass has been discounted for egg production. Including mortality during the diapause period, even at a very low rate of 0.001 $\mathrm{d}^{-1}$ for all stages, considerably increases the total carbon flux by a factor of about $80 \%$ over respiration alone. The overall flux thus ranges as high as between $3.6 \mathrm{gC} \mathrm{m}^{-2} \mathrm{yr}^{-1}$ (for $\mu_{\mathrm{i}}=0 \mathrm{~d}^{-1}$ ) and $5.3 \mathrm{gC} \mathrm{m}^{-2} \mathrm{yr}^{-1}$ (for $\mu_{\mathrm{i}}=0.001 \mathrm{~d}^{-1}$ ). A similar set of estimates, but for the higher value of $b$, range between $4.8 \mathrm{gC} \mathrm{m}^{-2} \mathrm{yr}^{-1}$ (for $\mu_{\mathrm{i}}=0 \mathrm{~d}^{-1}$ ) and $5.9 \mathrm{gC} \mathrm{m}^{-2} \mathrm{yr}^{-1}$ (for $\mu_{\mathrm{i}}=0.001 \mathrm{~d}^{-1}$ ).

There are significant regional variations in these flux estimates. The highest values are observed in the eastern regions of the Nordic Seas (Fram Strait, Greenland Sea and Iceland Sea), all with flux estimates in the range 3-6 $\mathrm{gC} \mathrm{m}^{-2} \mathrm{yr}^{-1}$. Flux estimates in the Norwegian Sea and Arctic Ocean are considerably lower with flux estimates of about $1 \mathrm{gC} \mathrm{m}^{-2}$ $\mathrm{yr}^{-1}$ or less. As might be expected, the greatest factor affecting these regional differences is the abundances of overwintering populations, ranging from 500 overwintering individuals for the lowest sequestration estimates to well over 10,000 overwintering individuals for the highest.

\section{Discussion}

The rain of detrital organic material out of the surface ocean is understood to be one of the main vehicles of the biological pump. The global average of the flux of this material that reaches depths of around $1000 \mathrm{~m}$ can be roughly estimated as 2-8 $\mathrm{gC} \mathrm{m}^{-2} \mathrm{yr}^{-1}$, and is the fraction that can be considered as sequestered; i.e., removed from contact with the atmosphere for about a $1000 \mathrm{yr}$ or so. These estimates are largely based on net annual surface productivity, usually constrained by nutrient budgets, and direct flux measurements by sediment traps. Growing evidence suggests that significant contributions to carbon sequestration are being supplied by overwintering populations of copepods in various parts of the global ocean. For instance, Neocalanus tonsus has been estimated to contribute between $2 \mathrm{gC} \mathrm{m}^{-2}$ $\mathrm{yr}^{-1}$ and $9 \mathrm{gC} \mathrm{m}^{-2} \mathrm{yr}^{-1}$ to sequestration in the Southern Ocean (Bradford-Grieve et al. 2001) while the combined contribution from Neocalanus copepods in the Pacific subarctic has been estimated at between $2 \mathrm{gC} \mathrm{m}^{-2} \mathrm{yr}^{-1}$ and $4 \mathrm{gC} \mathrm{m}^{-2}$ $\mathrm{yr}^{-1}$ (Kobari et al. 2003, 2008). Our estimates of 3-5 $\mathrm{gC} \mathrm{m}^{-2}$ $\mathrm{yr}^{-1}$ for C. hyperboreus in the Nordic Seas also compares to our previous estimates of $1-4 \mathrm{gC} \mathrm{m}^{-2} \mathrm{yr}^{-1}$ for $C$. finmarchicus in the more southerly reaches of the subarctic North Atlantic. For all of these estimates, a significant fraction of the sequestered carbon, whether through respiration or mortality, leaves the surface in the form of lipids-what we call the lipid pump. Since these lipids contain none of the limiting nutrients for surface primary production, and migrating copepods largely avoid sediment traps, contributions from the lipid pump are not included in previous estimates of the biological pump. There is clearly a case to be made that overwintering copepods are significant contributors to oceanic carbon sequestration, that this is a global phenomenon, and that this process has not as yet been accounted for in global carbon budgets.

In our current work, we have relied on a long history of studies into the distribution and abundance of overwintering populations of $C$. hyperboreus. Such observations are hard to come by given the season, the remote locations and the 

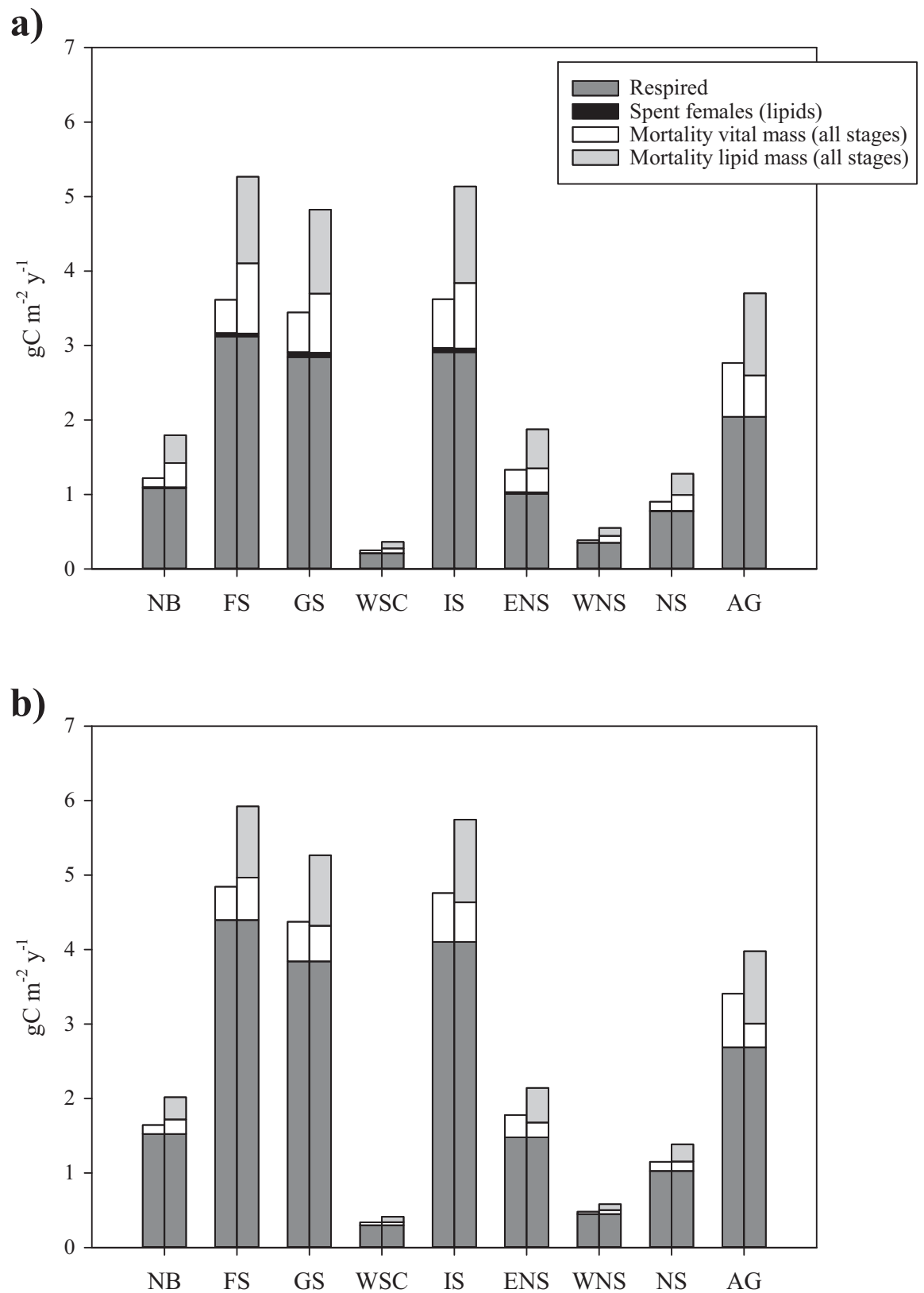

Fig. 3. Regional estimates of the carbon flux associated with overwintering populations of $C$. hyperboreus. Estimates are broken down as to respired flux, mortality flux of spent females lipid mass, mortality structural mass all stages, and mortality lipid mass all stages. Regional estimates Nansen Basin (NB), Fram Strait (FS), Greenland Sea (GS), W Spitzbergen Current (WSC), Iceland Sea (IS), E Norwegian Sea (ENS), W Norwegian Sea, (WNS) and Station $M$ in the Norwegian Sea (NS). The twin bars in both panels indicate estimates for zero mortality (other than spent females the left bar), and a low mortality rate of $0.001 \mathrm{~d}^{-1}$ (the right bar) for all stages. The two panels depict flux estimated for different metabolic rates parameter $b$. Panel (a) $b=2.5 \times 10^{-7} \mu \mathrm{gC}^{1 / 4} \mathrm{~s}^{-1}$ and (b) $b=5.0 \times 10^{-7} \mu \mathrm{gC}^{1 / 4}$.

depth to which observations have to be made. In all likelihood, our abundances are underestimates, as over-wintering populations are probably deeper than most sampling depths. Much of our distribution knowledge of this species comes from spring and summer campaigns, often conducted on the shelf or in relatively shallow fjords and often only covering the upper $200 \mathrm{~m}$ of the water column. In addition to abundance, a poorly constrained variable with large impact is the mortality rate of overwintering animals. We present two examples, one with no mortality (apart from spent females) and the other with very low mortality of $0.001 \mathrm{~d}^{-1}$ corresponding to a survivorship of $80 \%$ over the overwintering duration (Fig. 3). Mortality rates could easily be greater than this, and even a moderate increase to $0.005 \mathrm{~d}^{-1}$ would 
bring about sequestration fluxes in excess of $10 \mathrm{gC} \mathrm{m}^{-2}$ $\mathrm{yr}^{-1}$. Additionally, we present the outcome with different metabolic rate constants of $2.5 \times 10^{-7}$ and $5 \times 10^{-7} \mu \mathrm{gC}^{1 / 4}$ $\mathrm{s}^{-1}$ (panel $\mathrm{a}$ and $\mathrm{b}$ in Fig. 3). The consequence of higher metabolic rate is in moderate increase in the total flux. While respiration rate doubles, the length of diapause shortens from 8 months to less than 7 months for females, and from 7 to 3 months for stage CIII. A second consequence of higher metabolic rate is that females will be completely depleted after spawning. All of these considerations lend considerable uncertainty to our estimates although we do stress that in all cases we have tried to err on the side of caution. The three principal factors affecting this uncertainty in flux estimates, namely abundance, mortality and metabolic rate, are illustrated in Fig. 3. Further, the spreadsheet supplied in Supporting Information material will allow readers to judge for themselves the sensitivity of our estimates to particular parameter settings.

While the motivation for this work is partly to document how $C$. hyperboreus contributes to oceanic carbon sequestration, we feel it also important to address this in a more general sense. There are several copepod species in various regions of the global ocean that adopt similar life history strategies, and that locally, play key ecological roles. Specifically, there is a tight evolutionary coupling between zooplankton overwintering, the type and abundance of lipid available from their diet, the biochemical pathways by which dietary lipids are repackaged and stored, and the physical conditions found in their overwintering habitats. In this, lipids serve a triple purpose. They fuel metabolic costs during diapause (Hirche 1996; Lee et al. 2006), provide for capital breeding at an opportune time (Varpe et al. 2009; Sainmont et al. 2014), and provide a physical means for overwintering animals to achieve neutral buoyancy at depth (Visser and Jónasdóttir 1999; Pond and Tarling 2011). In part, it is the multipurpose use of lipids that makes these copepod species so successful, to the extent that they generally contribute a significant fraction of the local consumer biomass (Heinrich 1962), exerting significant predation pressure on the phytoplankton crop and their microzooplankton grazers while in turn being exploited as resources by forage fish.

In this sense, the significance of the lipid pump can be gauged in terms of the success of lipid-fuelled overwintering in the deep oceans as a life history strategy. We can speculate as to how global change might affect this success. In the first instance, there is the issue of changing phytoplankton community (Richardson and Schoeman 2004) and how this can affect not only the amount but type of lipid available to copepods. There is also the question of changes in deep water habitats as the pace and/or location of deep water formation changes (Rahmstorf et al. 2015). Increasing deep water temperatures not only increase respiration rates and thus decrease diapause durations, but also compromise ability of overwintering individuals to remain neutrally buoyant in these deep water habitats.

It is clear from this work, as well as previous studies, that the sequestration by overwintering zooplankton, while global in extent is far from uniform. There appear to be significant variations in intensity on the scale of 100 s of $\mathrm{km}$, with local hot spots and other regions with diminishing contributions. A landmark paper (Longhurst and Williams 1992) concluded that the carbon sequestered by seasonally migrating zooplankton was a minor contributor to the biological pump. This conclusion, drawn from a site in the North Atlantic, just happened to be in a location where practitioners of this life history strategy were scarce; likely due to the deep winter convection in this particular region that makes deep diapause less effective than in other areas. It was not until a more expansive mapping of overwintering populations was conducted (Heath et al. 2000) that a more complete regional estimate could be made (Jónasdóttir et al. 2015).

By way of conclusion, there is growing evidence of overwintering zooplankton populations in polar, subpolar, and temperate parts of the global oceans making significant contributions to oceanic carbon sequestration. The full extent remains unquantified as there are no easily obtained synoptic observations that can serve as proxies. Metabolic theory can certainly be used to constrain certain aspects for data poor species, although the abundance and distribution of overwintering populations remains the greatest unknown.

\section{References}

Abràmoff, M. D., P. J. Magalhães, and S. J. Ram. 2004. Image processing with imageJ. Biophotonics Int. 11: 36-41. doi: $10.1117 / 1.3589100$

Arrhenius, S. 1889. Über die Reaktionsgeschwindigkeit bei der Inversion von Rohrzucker durch Sauren. Z. Phys. Chem. 4: 226-248. doi:10.1002/cber.19310641113

Atkinson, A. 1998. Life cycle strategies of epipelagic copepods in the Southern Ocean. J. Mar. Syst. 15: 289-311. doi:10.1016/S0924-7963(97)00081-X

Auel, H., M. Klages, and I. Werner. 2003. Respiration and lipid content of the Arctic copepod Calanus hyperboreus overwintering $1 \mathrm{~m}$ above the seafloor at 2,300 $\mathrm{m}$ water depth in the Fram Strait. Mar. Biol. 143: 275-282. doi:10.1007/ s00227-003-1061-4

Bathmann, U. V., R. R. Makarov, V. A. Spiridonov, and G. Rohardt. 1993. Winter distribution and overwintering strategies of the Antarctic copepod species Calanoides acutus, Rhincalanus gigas and Calanus propinquus (Crustacea,Calanoida) in the Weddell Sea. Polar Biol. 13: 333-346. doi:10.1007/BF00238360

Bradford-Grieve, J. M., S. D. Nodder, J. B. Jillett, K. Currie, and K. R. Lassey. 2001. Potential contribution that the copepod Neocalanus tonsus makes to downward carbon 
flux in the Southern Ocean. J. Plankton Res. 23: 963-975. doi:10.1093/plankt/23.9.963

Brown, J. H., J. F. Gillooly, A. P. Allen, V. M. Savage, and G. B. West. 2004. Toward a metabolic theory of ecology. Ecology 85: 1771-1789. doi:10.1890/03-9000

Conover, D. O. 1992. Seasonality and the scheduling of life history at different latitudes. J. Fish Biol. 41: 161-178. doi:10.1111/j.1095-8649.1992.tb03876.x

Conover, R. J. 1967. Reproductive cycle, early development, and fecundity in laboratory populations of the Copepod Calanus hyperboreus. Crustaceana 13: 61-72. doi:10.1163/ 156854067 X00080

Daase, M., and K. Eiane. 2007. Mesozooplankton distribution in northern Svalbard waters in relation to hydrography. Polar Biol. 30: 969-981. doi:10.1007/s00300-007-0255-5

Daase, M., O. Varpe, and S. Falk-Petersen. 2014. Non-consumptive mortality in copepods: Occurrence of Calanus spp. Carcasses in the Arctic Ocean during winter. J. Plankton Res. 36: 129-144. doi:10.1093/plankt/fbt079

Edvardsen, A., J. M. Pedersen, D. Slagstad, T. Semenova, and A. Timonin. 2006. Distribution of overwintering Calanus in the North Norwegian Sea. Ocean Sci. 2: 87-96. doi: 10.5194/os-2-87-2006

Falk-Petersen, S., P. Mayzaud, G. Kattner, and J. R. Sargent. 2009. Lipids and life strategy of Arctic Calanus. Mar. Biol. Res. 5: 18-39. doi:10.1080/17451000802512267

Forest, A., V. Galindo, G. Darnis, S. Pineault, C. Lalande, J. E. Tremblay, and L. Fortier. 2011. Carbon biomass, elemental ratios $(\mathrm{C}: \mathrm{N})$ and stable isotopic composition $(\delta 13 \mathrm{C}, \delta 15 \mathrm{~N})$ of dominant calanoid copepods during the winter-tosummer transition in the Amundsen Gulf (Arctic Ocean). J. Plankton Res. 33: 161-178. doi:10.1093/plankt/fbq103

Gillooly, J. F., J. H. Brown, G. B. West, V. M. Savage, and E. L. Charnov. 2001. Effects of size and temperature on metabolic rate. Science 293: 2248-2251. doi:10.1126/science.1061967

Gislason, A., and O. S. Astthorsson. 1998. Seasonal variations in biomass, abundance and composition of zooplankton in the subarctic waters north of Iceland. Polar Biol. 20: 85-94. doi:10.1007/s003000050280

Gislason, A., and O. S. Astthorsson. 2002. The food of Norwegian spring-spawning herring in the western Norwegian Sea in relation to the annual cycle of zooplankton. Sarsia 87: 236-247. doi:10.1080/00364820260294860

Halvorsen, E. 2015. Significance of lipid storage levels for reproductive output in the Arctic copepod Calanus hyperboreus. Mar. Ecol. Prog. Ser. 540: 259-265. doi:10.3354/ meps 11528

Heath, M. R., J. G. Fraser, A. Gislason, S. J. Hay, S. H. Jónasdóttir, and K. Richardson. 2000. Winter distribution of Calanus finmarchicus in the Northeast Atlantic. ICES J. Mar. Sci. 57: 1628-1635. doi:10.1006/jmsc.2000.0978

Hirche, H. J. 1996. Diapause in the marine copepod, Calanus finmarchicus-A review. Ophelia 44: 129-143. doi: 10.1080/00785326.1995.10429843
Hirche, H. J. 1997. Life cycle of the copepod Calanus hyperboreus in the Greenland Sea. Mar. Biol. 128: 607-618. doi: $10.1007 / \mathrm{s} 002270050127$

Hirche, H. J. 2013. Long-term experiments on lifespan, reproductive activity and timing of reproduction in the Arctic copepod Calanus hyperboreus. Mar. Biol. 160: 24692481. doi:10.1007/s00227-013-2242-4

Hirche, H. J., and N. Mumm. 1992. Distribution of dominant copepods in the Nansen Basin, Arctic Ocean, in summer. Deep-Sea Res. Part A 39: 485-505. doi:10.1016/S01980149(06)80017-8

Hirche, H. J., and B. Niehoff. 1996. Reproduction of the Arctic copepod Calanus hyperboreus in the Greenland Sea-field and laboratory observations. Polar Biol. 16: 209-219. doi: $10.1007 / \mathrm{s} 003000050046$

Hirche, H. J., S. Muyakshin, M. Klages, and H. Auel. 2006. Aggregation of the Arctic copepod Calanus hyperboreus over the ocean floor of the Greenland Sea. Deep-Sea Res. Part I Oceanogr. Res. Pap. 53: 310-320. doi:10.1016/j.dsr.2005.08.005

Ingvarsdóttir, A., D. F. Houlihan, M. R. Heath, and S. S. J. Hay. 1999. Seasonal changes in respiration rates of copepodite stage V Calanus finmarchicus (Gunnerus). Fish. Oceanogr. 8: 73-83. doi:10.1046/j.1365-2419.1999.00002.x

Jónasdóttir, S. H., A. W. Visser, K. Richardson, and M. R. Heath. 2015. Seasonal copepod lipid pump promotes carbon sequestration in the deep North Atlantic. Proc. Natl. Acad. Sci. USA 112: 12122-12126. doi:10.1073/ pnas. 1512110112

Jung-Madsen, S., T. Gissel Nielsen, P. Grønkjær, B. Winding Hansen, and E. Friis Møller. 2013. Early development of Calanus hyperboreus nauplii: Response to a changing ocean. Limnol. Oceanogr. 58: 2109-2121. doi:10.4319/ lo.2013.58.6.2109

Kattner, G., and W. Hagen. 2009. Lipids in marine copepods: Latitudinal characteristics and perspective to global warming, p. 257-280. In M. Kainz, M. T. Brett, and M.T. Arts [eds.], Lipids in aquatic ecosystems. Springer.

Kiørboe, T. 2008. A mechanistic approach to plankton ecology. Princeton Univ. Press.

Kiørboe, T., and A. G. Hirst. 2014. Shifts in mass scaling of respiration, feeding, and growth rates across life-form transitions in marine pelagic organisms. Am. Nat. 183: E118-E130. doi:10.1086/675241

Kleiber, M. 1947. Body size and metabolic rate. Physiol. Rev. 27: 511-541.

Kobari, T., A. Shinada, and A. Tsuda. 2003. Functional roles of interzonal migrating mesozooplankton in the western subarctic Pacific. Prog. Oceanogr. 57: 279-298. doi: 10.1016/S0079-6611(03)00102-2

Kobari, T., D. K. Steinberg, A. Ueda, A. Tsuda, M. W. Silver, and M. Kitamura. 2008. Impacts of ontogenetically migrating copepods on downward carbon flux in the western subarctic Pacific Ocean. Deep-Sea Res. Part II 55: 1648-1660. doi:10.1016/j.dsr2.2008.04.016 
Kristiansen, I., E. Gaard, H. Hátún, S. H. Jónasdóttir, and A. Ferreira. 2016. Persistent shift of Calanus spp. in the southwestern Norwegian Sea since 2003, linked to ocean climate. ICES J. Mar. Sci. 73: 1319-1329. doi:10.1093/ icesjms/fsv222

Lee, R. F., W. Hagen, and G. Kattner. 2006. Lipid storage in marine zooplankton. Mar. Ecol. Prog. Ser. 307: 273-306. doi: $10.3354 /$ meps307273

Longhurst, A., and R. Williams. 1992. Carbon flux by seasonal vertical migrant copepods is a small number. J. Plankton Res. 14: 1495-1509. doi:10.1093/plankt/14.11.1495

Maps, F., S. Plourde, and B. Zakardjian. 2010. Control of dormancy by lipid metabolism in Calanus finmarchicus: A population model test. Mar. Ecol. Prog. Ser. 403: 165180. doi: $10.3354 /$ meps08525

Maps, F., N. R. Record, and A. J. Pershing. 2014. A metabolic approach to dormancy in pelagic copepods helps explaining inter- and intra-specific variability in life-history strategies. J. Plankton Res. 36: 18-30. doi:10.1093/plankt/ fbt100

Miller, C. B., B. W. Frost, H. P. Batchelder, M. J. Clemons, and R. E. Conway. 1984. Life histories of large, grazing copepods in a subarctic ocean gyre: Neocalanus plumchrus, Neocalanus cristatus, and Eucalanus bungii in the Northeast Pacific. Prog. Oceanogr. 13: 201-243. doi:10.1016/00796611(84)90009-0

Ohman, M. D., J. M. Bradford, and J. B. Jillett. 1989. Seasonal growth and lipid storage of the circumglobal, subantarctic copepod, Neocalanus tonsus (Brady). Deep-Sea Res. Part A 36: 1309-1326. doi:10.1016/0198-0149(89)90085-X

Østvedt, O. J. 1955. Zooplantkon investigations from weather ship $M$ in the Norwegian Sea, 1948-49. Hvalr. Skr. 40: $1-93$.

Pierson, J., H. Batchelder, W. Saumweber, A. Leising, and J. Runge. 2013. The impact of increasing temperatures on dormancy duration in Calanus finmarchicus. J. Plankton Res. 35: 504-512. doi:10.1093/plankt/fbt022

Plourde, S., P. Joly, J. A. Runge, J. Dodson, and B. Zakardjian. 2003. Life cycle of Calanus hyperboreus in the lower St. Lawrence Estuary and its relationship to local environmental conditions. Mar. Ecol. Prog. Ser. 255: 219233. doi:10.3354/meps255219

Pond, D. W., and G. A. Tarling. 2011. Phase transitions of wax esters adjust buoyancy in diapausing Calanoides acutus. Limnol. Oceanogr. 56: 1310-1318. doi:10.4319/ lo.2011.56.4.1310

Rahmstorf, S., J. E. Box, G. Feulner, M. E. Mann, A. Robinson, S. Rutherford, and E. J. Schaffernicht. 2015. Exceptional twentieth-century slowdown in Atlantic Ocean overturning circulation. Nat. Clim. Chang. 5: 1-6. doi:10.1038/nclimate2554
Richardson, A. J., and D. S. Schoeman. 2004. Climate impact on plankton ecosystems in the Northeast Atlantic. Science 305: 1609-1612. doi:10.1126/science.1100958

Sainmont, J., K. H. K. H. Andersen, Ø Varpe, and A. W. Visser. 2014. Capital versus income breeding in a seasonal environment. Am. Nat. 184: 466-476. doi:10.1086/677926

Saumweber, W. J., and E. G. Durbin. 2006. Estimating potential diapause duration in Calanus finmarchicus. Deep-Sea Res. Part II Top. Stud. Oceanogr. 53: 2597-2617. doi: 10.1016/j.dsr2.2006.08.003

Scott, C., S. Kwasniewski, S. Falk-Petersen, and J. Sargent. 2000. Lipids and life strategies of Calanus finmarchicus, Calanus glacialis and Calanus hyperboreus in late autumn, Kongsfjorden, Svalbard. Polar Biol. 23: 510-516. doi: 10.1007/s003000000114

Smith, S. 1995. The Arabian Sea: Mesozooplankton response to seasonal climate in a tropical ocean. ICES J. Mar. Sci. 52: 427-438. doi:10.1016/1054-3139(95)80058-1

Swalethorp, R., S. Kjellerup, M. Dünweber, T. G. Nielsen, E. F. Møller, S. Rysgaard, and B. W. Hansen. 2011. Grazing, egg production, and biochemical evidence of differences in the life strategies of Calanus finmarchicus, C. glacialis and C. hyperboreus in Disko Bay, western Greenland. Mar. Ecol. Prog. Ser. 429: 125-144. doi:10.3354/meps09065

Tsuda, A., H. Saito, and H. Kasai. 2004. Life histories of Eucalanus bungii and Neocalanus cristatus (Copepoda: Calanoida) in the western subarctic Pacific Ocean. Fish. Oceanogr. 13: 10-20. doi:10.1111/j.1365-2419.2004.00315.x

Varpe, Ø., C. Jørgensen, G. A. Tarling, and Ø. Fiksen. 2009. The adaptive value of energy storage and capital breeding in seasonal environments. Oikos 118: 363-370. doi: 10.1111/j.1600-0706.2008.17036.x

Visser, A. W., and S. H. Jónasdóttir. 1999. Lipids, buoyancy and the seasonal vertical migration of Calanus finmarchicus. Fish. Oceanogr. 8: 100-106. doi:10.1046/j.13652419.1999.00001.x

\section{Acknowledgments}

We would like to thank Jeppe Olsen for providing GIS assistance. This work is a contribution to the Centre for Ocean Life, a VKR Centre of Excellence supported by the Villum Foundation. Funding was also provided by the Danish Council for Strategic Research under the NAACOS project, and European Union Seventh Framework Programme Basin Scale Analysis, Synthesis and Integration (ENV.2010.2.2.1-1; www. euro-basin.eu).

\section{Conflict of Interest}

None declared.

Submitted 10 September 2016 Revised 09 November 2016 Accepted 11 November 2016 Associate editor: Ronnie Glud 